\title{
Self-made People
}

\author{
David Mark Kovacs \\ Bilkent University \\ david.mark.kovacs@gmail.com
}

\begin{abstract}
The Problem of Overlappers is a puzzle about what makes it the case, and how we can know, that we have the parts we intuitively think we have. In this paper, I develop and motivate an overlooked solution to this puzzle. According to what I call the self-making view it is within our power to decide what we refer to with the personal pronoun 'I', so the truth of most of our beliefs about our parts is ensured by the very mechanism of self-reference. Other than providing an elegant solution to the Problem of Overlappers, the view can be motivated on independent grounds. It also has wide-ranging consequences for how we should be thinking about persons. Among other things, it can help undermine an influential line of argument against the permissibility of elective amputation. After a detailed discussion and defence of the self-making view, I consider some objections to it. I conclude that none of these objections is persuasive and we should at the very least take seriously the idea that we are to some extent self-made.
\end{abstract}

\section{Overpopulation puzzles and the metaphysics of persons}

I am a person: a conscious, rational, thinking being. I also have various parts: feet, hands, a nose, ears, and so on. Moreover, I have parts that are or involve my 'thinking parts': a brain, a head, and things without a conventional name in English, for example my 'nose-complement' (a part that includes all of me except for my nose). For the sake of vividness, focus on my nose-complement. My nose-complement has everything intrinsically required for personhood: it has a working brain with the capacity to sustain a complex mental life. Worse yet, it has my brain, which makes it an excellent candidate for thinking just what I think. But if my nose-complement thinks of itself what I think of myself, it is badly mistaken. It is plausibly not a person, and it certainly does not have a nose. Unfortunately, things seem to my nose-complement exactly the way they seem to me. What makes it the case, then, that in referring to myself I refer to a person and not to a nose-complement? And how can I know that I am a person and not a nose-complement?

This is one of the many overpopulation puzzles widely discussed in the personal identity literature. However, my cursory presentation 
lumped together two different problems that ought to be distinguished. ${ }^{1}$ For clarity's sake, let me introduce some fresh terminology for them. The first problem I shall call the Problem of Almost-Persons. Here, we assume at the outset that even if our large composite proper parts are very similar to persons, they nevertheless fail to be persons. This does not automatically answer the following question: What makes it the case that when I use the word 'I', I refer to a person? I put the question in linguistic terms, but there is an equally pressing question about 'I'-thoughts. If I share my place with 'almost-persons' that ultimately fail to be persons. Then what makes it the case that my 'I'-thoughts pick out a person, rather than any of these non-persons? These questions have a distinctively metaphysical flavour, but the Problem of Almost-Persons also has an epistemological side: how can I know that I am a person? Whatever reasons I could cite for thinking that I am a person are also available to the non-persons overlapping with me. But if they think they are persons, they are wrong. And since I have no rational basis to tell myself apart from them, apparently $I$ cannot know that I am a person.

The second problem, which we could call the Problem of Overlappers, requires no specific assumption about personhood. Never mind if my nose-complement is a person. I firmly believe that I am not a nosecomplement; I have the boundaries of a human being and not those of a proper part of a human being. To borrow a pair of useful expressions from Madden (forthcoming), I am a humanoid, something that has human form. When I refer to myself and entertain various beliefs about what parts I have, these are normally true beliefs about a humanoid, not false beliefs about something that overlaps with a humanoid (an overlapper, to borrow another handy expression from Madden). For instance, when I utter the sentence 'I have a nose' and think the thought expressed by it, I say and think something true about a humanoid; I do not say and think something false about a nosecomplement. But why is this so? This puzzle too has an equally pressing epistemological aspect. If I think I have a nose and my nose-complement thinks that it has a nose, one of us is mistaken. But how can I know that I am not the one who is mistaken? More generally, how can I know that I have roughly the parts I think I have and am not an overlapper with a different set of parts? ${ }^{2}$

\footnotetext{
1 Thanks to an anonymous referee for helping me get clearer on the problems.

2 The Problem of Overlappers is more or less what Madden (forthcoming) calls the problem of thinking parts. I still prefer my terminology because Madden's label suggests that when
} 
The two problems are often discussed together, but they differ importantly: the Problem of Overlappers is about our parts, while the Problem of Almost-Persons is about our status as persons. Despite this difference, the two problems are importantly related in the following way. One may reasonably suppose that no acceptable solution to the Problem of Overlappers can deny that we are persons; it cannot turn out that when self-referring, some of us refer to non-persons. Call this the Person Constraint. The Person Constraint is highly plausible and suggests that the two problems are best approached together. To recap, this means that we need to answer the following four questions: (a) What makes it the case that our 'I'-thoughts and utterances pick out persons? (b) How can we know that they pick out persons? (c) What makes it the case that they typically pick out things with roughly the parts that we think we have? (d) How can we normally know that they pick out things with roughly the parts that we think we have? The rest of this paper will focus mostly on questions (c) and (d), the metaphysical and the epistemological aspects of the Problem of Overlappers. But it will also be necessary to discuss the Problem of Almost-Persons in some detail. There are two reasons for this. First, I want to show that there is a unified solution to the two problems. Second, I want to show that while my solution to the Problem of Overlappers is quite unorthodox, it honours the Person Constraint.

The two problems also share an important common feature: they make no assumption about uniqueness or referential indeterminacy. As I stated them, both are concerned with why we are, and how we can know that we are, entities with certain features. They assume neither that exactly one person-candidate is a person, nor that every token of 'I' determinately refers to one person-candidate. This is no accident. The Problem of Almost-Persons and the Problem of Overlappers are puzzles about self-reference and as such are specific to conscious, rational, thinking beings. But there is a completely general puzzle, Unger's (1980) famous Problem of the Many, which arises for all material objects, including persons. ${ }^{3}$ It is not entirely uncontroversial what exactly the problem is, but the phenomenon of boundary-vagueness

self-referring we always pick out the largest candidate, which has all the other candidates as proper parts. As should be obvious from the discussion to follow, I believe this assumption to be false. For more on these puzzles, see van Inwagen (1981), Olson (1995, 2007), Merricks (1998), Hawley (1998), Sider (2001b, 2003), Burke (2003), Zimmerman (2003a), Hershenov (2005), Hudson (2007), D. Kovacs (2010), and Sutton (2014).

3 See especially Hudson (2001, Ch. 1-2). 
plays a central role in it. Take, for instance, any ordinary chair. It is not clear where the boundaries of the chair are: there are mereological sums around the outskirts of the chair that do, and largely overlapping sums that do not, have certain particles. What prevents all those mereological sums from being chairs? And even if exactly one of them is a chair, which one is that? At least in part, this is a problem about referential indeterminacy: we intuitively think that when attempting to refer to a material object of kind $\mathrm{K}$ we determinately refer to exactly one K; moreover, we take ourselves to know which $\mathrm{K}$ we are referring to. The Problem of the Many threatens to show otherwise. It is important to make it clear that the Problem of Overlappers and the Problem of Almost-Persons do not concern boundary; they threaten widespread and massive error, not referential indeterminacy. In the actual world, where boundary-vagueness is rampant, it is easy to mistake these problems for special instances of the Problem of the Many. But the problems differ both in source and in scope and should not be confused. ${ }^{4}$

The rest of the paper will proceed as follows. In \$2 I will present two general approaches to the problems: deflationist and heavyweight views. In $\$_{3}$, I will introduce my preferred variety of deflationism, the self-making view: roughly, our 'I'-thoughts and utterances automatically pick out the best candidate referent in our vicinity. The view borrows a familiar idea from Harold Noonan (1998): when using the word 'I' only persons refer to themselves; non-persons refer to the persons they overlap with. As we shall see, the self-making view provides a nice solution to the Problem of Overlappers but can also be motivated by independent considerations about demonstratives and mental content. It also has some surprising (though to my mind attractive) consequences, which will be spelled out in $\$_{4}$. In $\$_{5}$ I will address several objections. I will argue that none of them are compelling, and we should treat the self-making view as a serious and largely overlooked competitor in the metaphysics of persons.

\footnotetext{
4 The two problems should also be distinguished from overpopulation puzzles that have to do with coincident, rather than merely overlapping, person-candidates, for example, the Problem of the Thinking Animal for non-animalist theories of personal identity and the 'revenge problems' that target animalism. For these puzzles, see Snowdon (1990), Olson (1997a), Noonan (1998), Shoemaker (1999), Baker (2000, pp. 207-8), Robinson (2006, pp. 255-8), Johnston (2007), Árnadóttir (2010), and Parfit (2012). Unlike these puzzles, the Problem of Overlappers and the Problem of Almost-Persons arise for any metaphysic of persons according to which we have 'thinking parts'.
} 


\section{Two approaches to the puzzles}

How should we go about solving the puzzles? Two broad strategies recommend themselves. (The literature rarely distinguishes between the Problem of Almost-Persons and the Problem of Overlappers, and in presenting the two strategies I will not pay too much attention to the distinction either. I will be more careful when presenting my own view.)

Heavyweight approaches attempt to find some metaphysically significant feature that distinguishes persons from their overlappers. The feature that most obviously comes to mind is existence: perhaps the problematic parts do not even exist. One may get rid of nose-complements and their kin by rejecting the Remainder Principle (RP), according to which for any $x$ and $y$, if $x$ is a proper part of $y$ then there is a $z$ composed exactly of those parts of $y$ that do not overlap $x$ (Simons 1987, p. 88). But in itself, this will not solve the puzzles; one would also need to eliminate composite proper parts whose existence is independently plausible, such as brains, heads and upper parts (those that sculptors represent with a bust). ${ }^{5}$ An alternative heavyweight strategy is to accept the existence of overlappers but maintain that they lack some intrinsic property required for personhood. Perhaps a thing's mental properties do not supervene on the microphysical properties of its parts, so our overlappers do not intrinsically qualify as persons (Merricks 1998). Or perhaps their parts lack certain natural functions necessary for personhood (Madden forthcoming). Either way, heavyweight approaches contend that the problematic person-candidates do not enjoy our metaphysically distinguished status.

By contrast, deflationist approaches posit no deep metaphysical difference between us and our overlappers and suggest instead that some general facts about the workings of thought and language guarantee that when self-referring, we refer to things with the right parts. These views are naturally paired with a more general deflationist attitude to the metaphysics of persons: the underlying thought is that most philosophical questions about people are primarily conceptual questions. ${ }^{6}$ This does not necessarily mean that the traditional puzzles surrounding persons are philosophically unimportant. Sider, for example,

\footnotetext{
${ }^{5}$ For this reason, Olson (1995) concludes that we have no composite proper parts at all.

${ }^{6}$ I am deliberately being somewhat vague here, since the view comes in so many different varieties. See, among others, Lewis (1976), Nozick (1981), Hirsch (1982, Ch. 10), Parfit (1984), Unger (1990), Rovane (1998), Sidelle (1999), Sider (2001a), and Eklund (2004).
} 
argues that the problem of personal identity is 'conceptually deep, even if metaphysically shallow' (2011, p. 74): theorizing about persons may shed light on crucial concepts like deliberation and moral responsibility but will not reveal much about the fundamental structure of the world. ${ }^{7}$

As of today, the most popular deflationist view about personal identity is conventionalism. A natural conventionalist approach to overpopulation puzzles would be that something about the meaning of the predicate 'is a person' guarantees that our self-referential attempts latch on to things with the features we normally attribute to them. A thoroughly public version of conventionalism would emphasize the role of social conventions. For instance, perhaps personhood is a maximal concept: the predicate 'is a person' is not applicable to proper parts of persons. ${ }^{8}$ A different kind of conventionalism may allow that different speakers have slightly different concepts corresponding to the same linguistic expression. ${ }^{9}$ Both kinds of conventionalism should be distinguished from a much more radical view, according to which persons are conventional constructs that depend for their existence on social conventions. ${ }^{10}$ Conventionalism as I understand it makes no such claim. It contends merely that it is a matter of convention which mind-independently existing things count as persons; which things exist mind-independently is not a matter of convention, on this view (cf. Olson 1997b, pp. 156-9 and Merricks 2001, p. 175).

In this paper, I will not discuss the standard versions of deflationism, nor will I criticize their heavyweight alternatives. Instead, I wish to propose a novel deflationist view and argue that we have reasons to take it seriously. According to the picture I shall advocate, we are

7 As an anonymous referee pointed out to me, the division between heavyweight and deflationist views is not necessarily sharp. According to reference magnetism, a view inspired by Lewis (1983), meaning is determined by use and intrinsic eligibility. One might think that various questions about the metaphysics of persons turn on the meaning of the predicate is a person', which is determined by what strikes the best balance between use and eligibility. Sider (2001a), who is otherwise sympathetic to magnetism, considers and rejects its application to personal identity. (I refer to magnetism merely as a view inspired by Lewis, since it remains controversial whether Lewis himself ever endorsed it; see Weatherson 2013 and Schwarz 2014.)

${ }^{8}$ See Burke (1994) and Sider (2001b, 2003). Note that the maximality principle does not provide a full solution, since it does not imply that my nose-complement is not a person. It implies merely that if the human organism I think I am is a person, then my nose-complement is not (cf. Olson 1995).

9 This is Jackson's (1998) general view about linguistic meaning.

${ }^{10}$ See Braddon-Mitchell and Miller (2004) and Miller (2013) for this view. 
partially self-made. By the claim that we are self-made I only mean something analogous to the social conventionalist view: within some yet to be specified constraints it is up to us what we refer to with the personal pronoun 'I', but it is not up to us what exists or what is a candidate referent of our use of 'I'. The self-making view, as I shall call it, yields a nice solution to the Problem of Overlappers: when I think that I have a leg, my belief is automatically true because for any candidate referent that lacks a leg, there is a better candidate that has one. The view is in part inspired by, and works best in tandem with, a theory of Harold Noonan's (1998) that has come to be known as Personal Pronoun Revisionism (PPR). (I adopt this name with some hesitation, since it is not obvious that the view is genuinely revisionary in character.) According to PPR, only persons can use the word 'I' to refer to themselves; non-persons can use it only to refer to the person they overlap with. Armed with PPR, the self-making view solves both the Problem of Overlappers and the Problem of Almost-Persons: when self-referring, we automatically refer to things that satisfy most of our 'I'-thoughts, and since these things are 'I'-referents, they are automatically persons.

The self-making view is not without predecessors. Other philosophers have argued that the kinds of changes a person can survive depend on that person's self-conception (Nozick (1981, p. 60) or her concerns and expectations (Johnston 1989, Braddon-Mitchell and West 2001). However, these approaches differ importantly from mine. First, as Eklund (2004) notes, these authors are at bottom interested in self-concern relativism, the view that the proper target of our prudential concern is to some extent up to us. By contrast, my interest is chiefly metaphysical (though the view has some interesting ethical consequences, as I will show in $\$ 4$ ). Moreover, these authors are typically interested in persistence over time, an issue I will have little to say about here; my primary concern is identity and composition at a time. Finally, and most importantly, while the view has its predecessors, the motivation I will offer for it is, so far as I know, entirely new. In the next section I will explain the self-making view in more detail and offer some reason to believe it.

\section{The self-making view}

I think I am a humanoid with a nose, rather than a nose-complement embedded in a humanoid. But of course, the Problem of Overlappers 
gives me pause: what makes it the case, and how can I know, that I thereby believe something true about a humanoid rather than something false about a nose-complement? A deflationist answer will posit a link between the intuitive correctness of such beliefs and the mechanism of self-reference. The specific link I propose is this: most of our 'I'-thoughts are true because they automatically refer to a candidate that makes them true. Take, for example, the belief I express when uttering the sentence 'I have a nose'. There are lots of things here that have a nose: a whole human organism, a leg-complement, a handcomplement, etc. Other things equal, these are better candidates for being referred to by my 'I'-thoughts than my nose-complement. But of course, other things are not equal: many of these candidates fare worse than my nose-complement when it comes to beliefs about my other parts. There is, however, a candidate that makes more of my beliefs true than any of my overlappers, a candidate that has all the parts I ascribe to myself. Since there is such a candidate, I do have these parts; and since I know that there is such a candidate, I know that I have them. This is why I am (and I know that I am) a humanoid, rather than a noseless overlapper. In slogan form, you are the best candidate satisfier of the 'I'-thoughts entertained in your vicinity. This slogan conveys the gist of my view, but it requires three qualifications. ${ }^{11}$

First, how should we understand the expression 'the "I"-thoughts entertained in one's vicinity'? Importantly, on my proposal, when I believe that I have a nose, my overlapper also believes that $I$ have a nose; it does not believe that it has a nose. There are many overlappers where I am, but when entertaining 'I'-thoughts they are all thinking of $m e$; I, on the other hand, am thinking of myself. While I am happy to say that my overlappers share my thoughts, it would be somewhat misleading (though true) to say that they share my de se or 'I'thoughts. This latter claim is naturally read as meaning that I and my overlappers believe the same things of ourselves. But that is not my view. My view is that my overlappers have numerically the same de $s e$ beliefs that I have, but from their perspective these beliefs are not de se at all; they are beliefs about me, not about them. Hence the technical expression "I"-thoughts entertained in one's vicinity'.

Second, for reasons unrelated to the Problem of Overlappers, it is of course possible to lack knowledge about what one's parts are, even if

\footnotetext{
${ }^{11}$ Thanks to Matti Eklund, Ted Sider, and an anonymous referee for pressing me to get clearer on the self-making view's commitments.
} 
there is a candidate that would make the requisite beliefs true. Suppose I hallucinate, and on that basis come to believe, that someone chopped off my right arm. Is my belief that I have no right arm a true belief about an arm-complement or a false belief about something that does have a right arm? Intuitively it is the latter, and the self-making view should not predict otherwise. The original slogan should be amended to take care of such cases. But such an amendment is also independently motivated. The Problem of Overlappers concerns an essentially indexical piece of information: even once all facts about the candidates and their parts are settled, these facts still do not guarantee that $I$ am not a handless overlapper; moreover, knowledge of all these facts at best equips me with knowledge that I am one of the candidates but fails to rule out that I am a handless overlapper. However, if I falsely believe that my right hand has been chopped off I also do not know various non-indexical truths about which candidates exist and what their parts are. The modified slogan, which is more in keeping with the spirit of the self-making view, can be stated as follows: You are the best candidate satisfier of those ' $I$ '-thoughts entertained in your vicinity that are not based on ignorance (lack of knowledge) about the relevant non-indexical truths.

The third qualification is best brought out by a natural but mistaken complaint against the self-making view. The objection is that the method of identifying us with the best candidate referents of our 'I'thoughts will not narrow down the number of candidates to one, so the self-making view does not solve the Problem of Overlappers. Since we have beliefs about our legs, arms, and nose but not about the electron in the tip of a hair that is on the verge of falling out, there will always be some indeterminacy about the reference of 'I'. In response, I should emphasize again that the Problem of Overlappers is a puzzle about why we are (and how we can usually know that we are) things with the parts we intuitively think we have. The threat this problem poses is not referential indeterminacy but massive and determinate error. Since the self-making view explains why we do not commit this kind of error, it solves the Problem of Overlappers. That it does not guarantee a single referent due to the widespread phenomenon of referential indeterminacy is simply beside the point. ${ }^{12}$

\footnotetext{
${ }^{12}$ What does the self-making view say about particles that obviously and determinately seem to be my parts but of which I have no beliefs either way? For example, what about a particular electron in the middle of my body? Cases like this do not pose a problem for the self-making view. Take a particular electron $e$ that is clearly a part of my right leg. While it is true that I have no beliefs about $e$, I do believe that the right leg is a part of me. So the best
} 
Nevertheless, the objection does show that there may be no such thing as the best candidate satisfier of our 'I'-thoughts. We can take this point and modify the slogan one last time as follows: You are one of the best satisfiers of those ' $I$ '-thoughts entertained in your vicinity that are not based on ignorance about the relevant non-indexical truths. This formulation allows for ties. But it is an unlovely mouthful, so in the interest of readability I will often leave the qualifications implicit and refer to the self-making view as the view that we are the best candidate referents of the 'I'-thoughts entertained in our vicinity. ${ }^{13}$

Hopefully, by now we have a sufficiently clear grasp of what the selfmaking view is. But do we have any reason to accept it? I think we do. Though I have no knock-down argument to offer, I would like to mention a few considerations that to my mind make the view very attractive. These fall into two categories. First, we have 'bottom-up' considerations: the self-making view dovetails with plausible views about demonstrative reference and mental content. Second, there are 'top-down' considerations: the self-making view has great problem-solving potential. ${ }^{14}$

Let us start with the 'bottom-up' motivations. It is customary to distinguish between pure indexicals ('I', 'today', 'tomorrow') and true demonstratives ('this', 'that', 'she', 'he'). The difference is, roughly, that while the reference of a pure indexical is secured 'automatically' by its meaning and the context (Perry 1997, pp. 595-6), in the case of true demonstratives some extra effort is required - perhaps a physical demonstration (Kaplan 1989a, Reimer 1991) or certain directing intentions (Kaplan 1989b, Bach 1992, Perry 1997, p. 595). An interesting intermediate group includes demonstratives such as 'here' and 'now'. Arguably, these demonstratives are like pure indexicals in that their meaning and context put automatic constraints on their reference. But they are like true demonstratives in that these constraints leave standing more than one candidate referent. Typical

candidate referent of my 'I'-thoughts is something that has the right leg. But parthood is transitive. So this best candidate also has $e$ as a part. The self-making view does not imply that to have some $x$ as a part it is necessary to believe that one has $x$ as a part.

${ }^{13}$ Hawthorne (2006) briefly entertains a view somewhat similar to my self-making view. This view does not seem to allow for ties, since Hawthorne presents it as a proposal about how to precisify the vague predicate 'is a person'. As should be clear by now, I think that the Problem of Overlappers should be sharply distinguished from any problem having to do with vagueness.

14 Thanks to an anonymous referee for helping me appreciate the importance of the bottom-up motivations. 
uses of 'here' refer to the speaker's location, but there can be considerable variation in the extent of this location: it can be the speaker's immediate vicinity, her room, her apartment, etc. Mutatis mutandis for 'now': in every context it refers to the time of the utterance, but the span of that time is not constant. ${ }^{15}$ We could say that the reference of such indexicals is secured 'quasi-automatically' and, following Recanati 2001, call them impure indexicals: their meaning and context puts automatic constraints on their reference, but these constraints leave some wiggle room that we do not find in pure indexicals.

Whether the reference of true demonstratives depends on the speaker's intention is a controversial issue. But it seems evident that intention plays a role in determining the reference of impure indexicals such as 'here' and 'now'. This is not to say that in the absence of such an intention, 'here'- and 'now'-utterances are vacuous; perhaps they have an element of indeterminacy and still come out true on every precisification, as in 'There are no mammoths here'. I am making a much weaker claim: in central cases, when the speaker knows the relevant non-indexical truths, her intention constrains the indexical's reference so as to make her utterance true. Suppose that sitting in my chair, I look to the right and see my cup on the table. I then utter 'The cup is here'. The reference of 'here' is quasi-automatic: it has to include my exact location, but it can also include more. One might then ask what makes it the case that I truly said of a spatial region including my table that my cup was present in it, rather than saying this falsely of a smaller region not including the table. Arguably, the answer is simply that to some extent it is up to me which place I refer to when I say 'here', and I had in mind a region that included the table. There are limits to this; for instance I could not mean your table if you lived thousands of miles away from me. But within certain constraints, I can simply decide to use 'here' so as to include my table. Similar remarks apply to 'here'- and 'now'-thoughts. If looking to the right I see that my cup is on the table, my thought that the cup is here is very easily truetrue simply because I know the relevant non-indexical truths, and the table is within the range of locations I can think of as 'here'.

\footnotetext{
${ }^{15}$ Kaplan includes 'here' and 'now' on his official list of pure indexicals, but as he points out they both suffer from a certain amount of vagueness (1989a, p. $491 \mathrm{fn} .12$ ).

${ }^{16}$ Recanati (2001) presents essentially this view about 'here' and 'now' as more or less the standard view in the literature. Like most philosophers of language writing on indexicals, Recanati focuses on utterances involving 'here' and 'now' and is less concerned with 'here'and 'now'-thoughts.
} 
Now, 'I' is almost invariably treated as belonging to the same group of pure indexicals as 'today' and 'tomorrow'. However, the Problem of Overlappers should make us realize that it is in fact closer to 'here' and 'now'. In every context, several overlapping locations are intrinsically eligible to be picked out by 'here'. Likewise, in every context several person-candidates are intrinsically eligible to be picked out by 'I'. This may be puzzling, but luckily a solution naturally recommends itself. Above I have suggested that our 'here'-thoughts and utterances are usually true because we have some freedom about which place we pick out with them. The truth of most of our 'I'-thoughts can be explained in a similar way. I know that there is at least one entity here that has four limbs, and this entity is intrinsically eligible to be the referent of my 'I'-thought. So my belief that I have four limbs is easily true - just as easily as my belief that the cup is here. To be sure, as a matter of fact 'I' shows more stability in its reference than 'here': with a few exceptions (which I will discuss in \$4), most of us consistently use 'I' to refer to a humanoid. But I maintain that this difference is only one of degree. If that is right, we get the following argument for the self-making view. That our intentions have a role in reference determination (or at least reference constraining) is highly plausible for impure indexicals such as 'here' and 'now'; the Problem of Overlappers gives us reason to think that 'I', too, is an impure indexical; and so it is natural to accept that our intentions play a similar role in constraining the reference of our 'I'-thoughts. But to accept this is to accept the self-making view.

To my mind, the aforementioned analogy with 'here' is already quite suggestive. But the self-making view also dovetails nicely with a plausible big-picture theory of mental content, advocated in a series of papers by David Lewis. ${ }^{17}$ Lewis's core question is how the objective facts determine mental content, and his starting point is the platitude that mental states are caused by experiential input and cause behaviour. This raises a version of the problem of radical interpretation: a mental state's experiential input and behavioural output still underdetermine its content. Lewis thinks that to overcome this problem we need to appeal to certain basic principles of folk psychology, 'our

\footnotetext{
17 See Lewis (1974, 1979, 1983,1994). I follow Weatherson (2013) and Schwarz (2014) in assigning a rather limited role to naturalness in Lewis's theory of content. But even if I turned out to be wrong, this would not matter to the present discussion, since the various overlapping person-candidates plausibly do not differ in their naturalness enough for this to tip the scale (See Sider 2001a for a similar point about identity over time.) For a related, Davidsonian line of thought, one with quite different results, see Madden (2011b).
} 
general theory of persons' (1974, p. 334). One such principle is that a subject's attitudes generally rationalize her behaviour; other things equal, a subject's beliefs are sensitive to her evidence and apt to cause behaviour that fits her goals. On Lewis's view, these general constraints are constitutive of mental content: we cannot believe or desire things that are unfit to be believed or desired.

Lewis never discusses the Problem of Overlappers ${ }^{18}$, but his theory of content suggests a plausible way to attack it. Consider a set of overlapping person-candidates whose behaviour and speech acts indicate that they believe of something in their vicinity that it has human form. Our task is to determine the content of these beliefs. The epistemological upshot of the Problem of Overlappers was that the candidates did not differ with respect to their evidence. It would be in Lewis's spirit to start with the 'I'-predications, leave open their subject, and ask which referent the 'I'-thoughts are fit to be believed about. The mere fact that the candidates have the same evidence does not prevent them from knowing certain truisms, for example that no limb-complement has four limbs. This helps determine what is and what is not fit for them to believe. If they say, 'I have two hands and two legs', we can take them to express a belief about a humanoid. If instead we took them to express a belief about a leg-complement, we would violate a principle of constitutive rationality: since the leg-complement obviously does not have four limbs, we would thereby assign to a person content that clearly does not fit her evidence. I do not want to suggest that Lewis himself would accept this reasoning. But the self-making view strikes me as a natural application of the general Lewisian idea that constitutive rationality plays a role in the determination of content.

We can now turn to 'top-down' considerations in support of the self-making view. As I already argued, the view provides a nice solution to the Problem of Overlappers. But in doing so, it also displays a further virtue: it is structurally similar to an elegant solution to the Problem of Almost-Persons. Taking this solution on board, we get a unified treatment of two closely related puzzles in the metaphysics of persons. According to Noonan's PPR, the first-person pronoun can only refer to persons. When an overlapper uses the word 'I' it does not refer to itself but to whichever person it overlaps. ${ }^{19}$ I find this proposal

\footnotetext{
${ }^{18}$ He does discuss the Problem of the Many (Lewis 1993), which, recall, is a very different problem.

19 See Noonan $(1998,2001$, and 2010). Note that Noonan himself employed the idea to solve the Problem of the Thinking Animal, while I am applying it to persons and their overlappers.
} 
attractive. Note, however, that it only solves the Problem of AlmostPersons; it leaves the Problem of Overlappers completely untouched (not that Noonan suggests otherwise). For instance, it implies that when I say or think 'I' I refer to a person, but it does not ensure that this person is not a nose-complement. The self-making view solves this problem: I am a humanoid and not a nose-complement because when I think or say 'I', I refer to the best candidate referent of my 'I'-thoughts, and the best candidate is a humanoid and not a nosecomplement. So there is nothing metaphysically special about the entity that has my boundaries (which are the boundaries of a humanoid) as opposed to the boundaries of my nose-complement. The only sense in which the humanoid is special is that it happens to be the best candidate referent of my ' $\mathrm{I}$ '-thoughts.

The self-making view also gives a non-mysterious explanation of how we can know that we have the boundaries we have. It is not because there is, despite our great physical similarity, a deep metaphysical difference between us and our overlappers that somehow prevents the latter from even being candidate 'I'-referents. It is also not because we possess extraordinary epistemic powers that help us make extremely fine-grained distinctions among several overlapping objects, some of which differ from us only in negligible respects. Nor is it by relying on some very strong form of externalism that in effect denies that the Problem of Overlappers poses any epistemological challenge. ${ }^{20}$ Rather, our overlappers are metaphysically on a par with us, our capacities are fairly ordinary, and so is the world we inhabit with respect to its epistemic friendliness. Yet these ordinary capacities and circumstances are just good enough. All we need is to be able to distinguish between the candidates and our surroundings. If the world contributes in the not overly demanding sense of containing enough candidates to make our 'I'-thoughts true, we do not have to be metaphysically distinguished, extraordinarily lucky, or particularly sophisticated to know that we are what we typically think we are.

Clearly, Noonan's PPR plays an important role in my account. One reason is the aforementioned structural similarity: in each case, the strategy is to say that I cannot be the wrong sort of thing because when that thing says or thinks 'I', it refers to me rather than itself. But there is also a second, equally important reason. In conjunction with the earlier

\footnotetext{
${ }^{20}$ Madden (forthcoming) presents and dismisses such a response. The idea is that if I were a hand-complement I would not possess the same evidence for having a hand that $\mathrm{I}$ in fact possess, since it would not even be true that I have a hand. I side with Madden in finding this answer unsatisfactory.
} 
mentioned Remainder Principle $(\$ 2)$, my view has the surprising consequence that some of us are hand-, arm-, and leg-complements. Those who think that persons cannot be proper parts of humanoids may then object that the self-making view implies that some 'I'-referents are not persons, thereby violating the Person Constraint. We can stave off this worry by combining the self-making view with PPR: since 'I' always refers to a person, 'I'-referents that are proper parts of humanoids are indeed persons. So the self-making view is perfectly compatible with the Person Constraint; what has to be rejected is the assumption that persons always have human form. I turn to these issues in the next section.

\section{Self-making and Body Integrity Identity Disorder}

The self-making view itself might sound strange at first glance, but as we have seen, in most cases it delivers intuitive results. Things are a bit different for people who hold unusual beliefs about their parts. Take, for example, Body Integrity Identity Disorder (BIID), a rare psychological condition often categorized as a mental illness. Patients suffering from this condition believe that at least one of their healthy limbs does not belong to them and that they could live a happier life without that limb. ${ }^{21}$ (This is a controversial description; some would say that most BIID patients accept that as a matter of fact they have the unwanted limb and only believe that they should not have it. ${ }^{22}$ Never mind: what is essential to the point of this section is the belief that one does not have a body part that one appears to have. If you think BIID is not a genuine example of that, replace every future occurrence of 'BIID' with 'the belief that one does not have a certain body part'. ${ }^{23}$ )

In the bioethics literature, there is a heated debate about the moral permissibility of elective amputation. $^{24}$ The details of this debate

${ }^{21}$ Here and in what follows, I assume that some $x$ belongs to S if and only if $\mathrm{S}$ has $x$ as a part.

${ }^{22}$ Bayne and Levy (2005) cite a survey, according to which only $13 \%$ of BIIDs reported that the unwanted limb was not their own.

${ }^{23}$ I am also assuming that BIID patients' de se beliefs are consistent. For instance if a BIID patient is attached to a left leg with a birthmark on it, he does not believe both that he does not have the left leg and that he has the birthmark. When such inconsistencies arise, the best candidate referent has to be settled on a case-by-case basis: which belief is more central in the patient's belief system? For the sake of simplicity, I stick to cases in which the patient's beliefs about his parts are clearly fully consistent. (Thanks to an anonymous referee for raising this worry.)

${ }^{24}$ See Bayne \& Levy (2005), Levy (2009), and J. Kovacs (2009) for arguments in defence of, and Müller (2009) for arguments against elective amputation. 
should not concern us here; I just want to draw attention to the widely shared assumption that when BIID patients believe that their unwanted limbs do not belong to them, they are irrational and strictly speaking wrong. The two claims are not independent of each other: the assumption is that BIID patients are obviously wrong about their body parts and, since their mistake cannot plausibly be explained as epistemically blameless, they are irrational too. Why? The bioethics literature does not go into that, but presumably the answer is roughly that the patients do not respond appropriately to their evidence: they have perceptual and proprioceptive evidence that they have certain limbs (they neither hallucinate nor experience lack of control), yet they deny that they have the limbs in question. Now of course the irrationality hypothesis does not by itself settle the dispute, for perhaps we have good moral reasons to respect some irrational and false beliefs. But the hypothesis nicely explains why the issue is so controversial: it would be much more difficult to show that there is even a prima facie moral problem with elective amputation if the patients' beliefs were neither false nor irrational.

However, if the limb-complements in question exist, the self-making view appears to block the implicit reasoning behind the irrationality hypothesis. When some 'I'-thoughts are entertained in the vicinity of a set of overlapping person-candidates, they refer to their best candidate referent. If that is right, a case can be made that BIID patients are neither irrational nor mistaken about their parts. Take a host of overlapping candidates that display the symptoms of BIID. These candidates share the 'I'-thought expressible by the English sentence 'I have exactly three limbs'. Here is the crux: there is a candidate to make this thought true. Of course this candidate is attached to a limb, but he does not have it as a part. So we have reason to treat the limb-complement as the referent of the 'I'-thoughts entertained in the candidate's vicinity, given that it is a better satisfier of these thoughts than the humanoid containing it. You might think that people just cannot be undetached limbcomplements, so all that follows is the absurd conclusion that in some cases the candidate picked out by the 'I'-thoughts is not a person. This is where Noonan's PPR comes into action: since 'I' can only refer to persons, the undetached limb-complement is a person, but the humanoid containing it is not. So some persons, namely BIID patients, are undetached limb-complements.

At this point, one may wonder if this is a proper application of the self-making view: is it not just obvious that BIID patients are irrational because they do not respond appropriately to their evidence? 
No, it is not. Unlike my imagined hallucinator in \$2, BIID patients are not ignorant about the relevant non-indexical truths. They are fully aware that there is a humanoid in their vicinity, and they perceive and feel the unwanted limb - they just do not think they have it as a part. But this is not at all incompatible with their evidence. The epistemological moral of the Problem of Overlappers is that our usual sources of evidence do not distinguish between us and our overlappers: they equip us only with knowledge that something with our thinking parts has such and such parts, not that we have such and such parts. Of course we can (and typically do) treat the largest candidate as the referent of our 'I'-thoughts, but doing so is by no means forced by our evidence. So BIID patients do not respond badly to their evidence by not following suit. But then, we are left with no good reason for thinking that they are irrational.

BIID patients are not humanoids who are wrong about their parts. They are exactly what they think they are: limb-complements enclosed in humanoids. Moreover, they are not irrational in thinking so. I have to admit that it is not just that I do not find this implication absurd or outrageous. I find it liberating: it makes metaphysical sense of the often-heard slogan 'You are what you think you are'. Elective amputation has sometimes been compared to sex reassignment surgery in that those opting for it often feel that they were 'born in the wrong body' (J. Kovacs 2009, p. 44). I want to suggest that in the case of BIID patients, even this is an understatement: they already have the right body and are just surrounded by the wrong accessories.

That at the end of the day BIID patients' beliefs about their parts are neither false nor irrational is, I realize, a surprising consequence of the self-making view and the Remainder Principle, a consequence that some would even take to be a reductio. I have little to say in response other than that I do not find this consequence counterintuitive at all, and until I see a positive argument to the contrary, I happily embrace it. In the next section I will consider some objections that I take to be more serious. As we will see, none of them are compelling, but they provide ample opportunity to further refine and clarify the view.

\section{Objections and answers}

\subsection{Self-reference and 'I'-thoughts}

PPR does double duty in my account. For one, it ensures that the view respects the Person Constraint. For another, it helps give a unified 
solution to the Problem of Overlappers and the Problem of AlmostPersons. In this sub-section I address two objections to the claim that when using the personal pronoun 'I' only persons refer to themselves, while their overlappers refer to the persons they overlap. The first one is that this claim is simply false. The second is that even if true, it is of no help in solving the Problem of Overlappers.

Let me start with the first worry. Madden maintains that:

[T] here is no evident reason to think that our use of the first-person pronoun is governed by a convention of referring to any particular kind of object. It is improbable that the standing meaning of a word such as 'I' embodies any restriction on the kind of thing to which it may refer. (Madden forthcoming, \$2.2)

Now, it is clear from the context that by 'kind' Madden means something with certain persistence conditions (see also Madden 2011a, p. 345), and I agree with him that the semantics of 'I' has no built-in restriction on the persistence conditions of its referent. However, PPR imposes no such restriction; all it requires is that whatever 'I' refers to also falls under the predicate 'is a person', whether the property of being a person determines persistence conditions or not. This weaker thesis retains Noonan's core insight that it is something like a conceptual truth that the first-person pronoun can only refer to persons. And I maintain that pace Madden this view is plausible, once stripped of the essentialist connotations.

Elsewhere, Madden (2011a) argues against PPR in a slightly different way. The gist of his objection is as follows. The best non-circular explanation of the intention to self-refer is that the intention's content is a repeatable act of the form $x$ refers to $x$. But since an overlapper (or in Madden's discussion, an animal) is able to entertain the thought $x$ refers to $x$, it is also able to self-refer. In response, we can grant the general rule that self-reference involves grasping the thought $x$ refers to $x$ but maintain that a successful self-referential use of 'I' also requires that one be a person. Madden asks what, given their grasp of what it is for an $x$ to refer to $x$, could possibly prevent non-persons from referring to themselves. The answer is 'Nothing'. The claim has never been that the overlappers are unable to refer to themselves. The claim is merely that they cannot have self-referential 'I'-thoughts. ${ }^{25}$

Let me now turn to the second concern: even if PPR is correct, there is an aspect of the Problem of Overlappers that neither it nor my selfmaking view can solve (Olson 1997b, 2002, Madden forthcoming). The

${ }^{25}$ Noonan (2001, p. 328) makes a similar point. 
problem is supposed to be that even if my overlappers cannot use the word 'I' to refer to themselves, it does not follow that they cannot think of themselves in the first-person mode. Perhaps when I open my mouth and say, 'I have two hands' the semantics of 'I' ensures that my handless overlapper also says something true. But the overlapper is not thereby prevented from falsely believing that it has a hand, even if it cannot give linguistic expression to this belief. And so I still do not know that I am not a handless overlapper.

While Noonan usually formulates PPR as a view about the linguistic expression 'I', I have all along been talking both about first-person language and first-person thought. There is one place where Noonan indicates that his account is also intended to apply to ' $\mathrm{I}$-thoughts: 'there is no ignorance of the kind Olson describes', he writes, 'because there is no expressible thought whose truth-value is unknowable in the way he thinks' (2001, p. 328). I want to give essentially the same answer. When I think the thought expressible by the sentence 'I have a nose', there is only one thought entertained here. Of course, my overlappers can and do have 'I'-thoughts, but these are numerically identical to my 'I'thoughts. And since my 'I'-thoughts refer to their best candidate referent, there is no room left for my overlappers' 'I'-thoughts to refer to anything else - otherwise they would not be numerically identical to my 'I'-thoughts. (They would have different content — see \$5.3.)

This last claim might be exactly what Olson and Madden tacitly reject: perhaps they think that my overlappers' thoughts are qualitatively indistinguishable but numerically distinct from mine. Motivated by this intuition, they could try to distinguish the Problem of Overlappers from the Problem of Overlapping Thoughts: which of the many qualitatively indistinguishable sets of thoughts is mine, and how can I know which one is mine? I agree that neither PPR nor my self-making view solves this problem. However, I also think that there is no such problem to begin with. The reasoning that led to the Problem of Overlappers simply does not generate anything like the Problem of Overlapping Thoughts. ${ }^{26}$

One might try to argue that the Problem of Overlapping Thoughts is easily generated once we accept a Fregean conception of 'I'thoughts. On the Fregean conception, 'I'-thoughts are constituted by private and unshareable senses, so no two subjects can share

\footnotetext{
${ }^{26}$ For a similar distinction, see McMahan (2002, p. 105) and Zimmerman (2003a, p. 508). McMahan takes it to be obvious that there is no such thing as the Problem of Overlapping Thoughts.
} 
numerically the same 'I'-thought. Following Morgan (2009), call this the Unshareability Claim (UC). The usual motivation for UC lies in a functionalist account of first-person thought. Functionalist views characterize the essence of 'I'-thoughts in terms of the perceptual or proprioceptive input that generates them and the behavioural output they produce. ${ }^{27}$ Morgan, for example, argues that any functionalist account has to accept at least one of the following claims: (i) only my 'I'-thoughts are sensitive in a direct way to gaining perceptual information from this particular point of view; (ii) only my 'I'thoughts are sensitive to proprioceptive information gained via this particular body; and (iii) only my 'I'-thoughts directly produce behaviour in this body. As a result, any functionalist account of firstperson thought entails UC (Morgan 2009, pp. 73-4).

Of course, functionalism about 'I'-thoughts is a controversial thesis. But we do not need to take a stance on it to see that we cannot rely on (i), (ii), or (iii) to support UC, since in light of the Problem of Overlappers we have reason to reject each of these principles. Principles (i) and (ii) are obviously based on the assumption that distinct subjects never gain the same perceptual and proprioceptive input through the same body. But I and my overlappers do have the same input: we share a point of view from which everything looks and feels the same. Similar remarks apply to principle (iii). It may be true that two disjoint subjects' behaviour is never produced by the same thoughts. But my thoughts do produce behaviour in my overlappers, and my overlappers' thoughts also produce behaviour in me. It seems, then, that people and their overlappers pose counterexamples to (i), (ii), and (iii). The somewhat ironic upshot is that UC, the extra premiss needed to get from the Problem of Overlappers to the Problem of Overlapping Thoughts, is undermined by the Problem of Overlappers itself.

These brief remarks are not intended to refute functionalism about 'I'-thoughts. My point is merely that the Problem of Overlappers gives us ample reason to reject UC as formulated above, and weaker formulations will not generate the Problem of Overlapping Thoughts. So we have been given no reason for thinking that our overlappers may have false but inexpressible beliefs about themselves.

The objections discussed so far are directed at an aspect of my view that it shares with Noonan's. In the remainder of this section, I will

\footnotetext{
27 See Evans (1981) for a classic defence of the Fregean-functionalist view.
} 
address potential complications that are specific to the self-making view.

\subsection{The limits of self-making}

I am the best candidate referent of the 'I'-thoughts entertained in my vicinity. But when is something a candidate referent of my ' $\mathrm{I}$ 'thoughts? Some cases seem obvious. My undetached headless torso, for instance, does not have my thinking parts and so cannot think my 'I'-thoughts. Neither can subjects disjoint from me: though they can have thoughts, they lack my thinking parts, which they would need in order to have these 'I'-thoughts. Generally, we can accept the following constraint on what can be a candidate referent of a set of 'I'-thoughts:

Thinking Parts Constraint: If $\mathrm{S}$ is a candidate referent of the 'I'-thoughts entertained in S's vicinity, then $S^{*}$ is a candidate referent of those 'I'thoughts only if $S^{\star}$ shares those of $S$ 's parts that are minimally sufficient for having 'I'-thoughts.

The Thinking Parts Constraint does not provide a non-circular definition of candidacy. Indeed, I doubt such a definition is possible. ${ }^{28}$ The idea is that we all have a clear grasp of paradigm cases, which we can then use to circumscribe the less obvious ones. A whole human organism is undoubtedly a candidate referent of the 'I'-thoughts entertained in its vicinity even if (as in the case of BIID patients) it ultimately fails to be a referent of those thoughts. The constraint also shows why we are not committed to certain implausible cases of self-making: insofar as they lack thinking parts head-complements and corpses are not even candidate 'I'-referents. The self-making view clearly has its limits: we should identify BIID patients with limb-complements, but as these examples show, not just anything goes. ${ }^{29}$

Another interesting question that is not settled by the Thinking Parts Constraint is whether persons can have humanoids as proper

${ }^{28}$ That would presumably require a descriptivist view of 'I', which is widely thought to be untenable due to arguments by Perry (1979) and others.

29 Motivated by familiar externalist 'slow switching' scenarios, Madden has recently defended a kind of 'best-candidate' theory of self-reference according to which it is sometimes possible for a dead organism to be the true referent ' $\mathrm{I}$ ' if it is the best knowledge-maximizing assignment to 'I' (2011b, pp. 309-15). Despite some similarities, my view is importantly different from Madden's. First, Madden presupposes an animalist theory of personal identity and, as we have seen, rejects the Person Constraint. Second, the self-making view is chiefly concerned with self-reference at a time and our knowledge thereof in ordinary cases, while Madden's main interest lies in identity over time, especially in certain extraordinary cases. My preferred approach to identity over time is also quite different from Madden's, but one that I lack the space to get into here. 
parts (rather than being embedded in them). Can a person, for instance, use 'I' to refer to the mereological sum of a humanoid and an artificial organ or prosthetic limb? Of course, for this question to even arise the mereological sum in question has to exist. And for that, we have to make assumptions stronger than the ones needed to generate the Problem of Overlappers, and stronger even than those needed to derive the surprising consequences for BIID patients. We have to assume not just that undetached thinking parts exist but also a very liberal theory of composition, presumably universalism (the view that any arbitrary $x \mathrm{~s}$ in any arrangement have a mereological sum). But on the assumption that such part-humanoid sums do exist, I remain open to the possibility that some of them are 'I'-referents and therefore persons. ${ }^{30}$ In that case, we can take some people to literally have their artificial organs or prosthetic limbs as parts if they think they have them. ${ }^{31}$ I will not argue for this view here. Suffice it to say that the Thinking Parts Constraint does not rule it out, and I consider this a good thing.

Can we say anything more general? Is, for example, the whole world or the mereological sum of two conscious beings a candidate for being me? If not, why not? Instead of offering a fully general answer, I wish to point out that several independently plausible intrinsic constraints on persons deny such things candidacy, and nothing in the selfmaking view forces us to give up these constraints. For example, we might want to maintain that any person must satisfy certain minimal requirements of physical or psychological unity so that the mereological sum of two physically disconnected things or two distinct loci of consciousness is never even a person-candidate. More generally, the self-making view is compatible with many different takes on what sorts of things we are: essentially psychological, phenomenal or biological beings, or what have you. My own view is that we cannot say anything general about what kinds of things we are other than that we are material objects. But this is not mandatory. All the self-making view officially requires is that whatever intrinsic conditions something has to meet to be a referent of a token of 'I', several objects satisfy that

\footnotetext{
${ }^{30}$ It is interesting to note that the personhood of such things is perfectly compatible with Williams's part-intrinsicality thesis, according to which any nomically possible duplicate of a person is a proper or improper part of a person (2013, p. 442).

${ }^{31}$ It is difficult not to notice that this line of thought is a natural extension of the extended mind hypothesis, famously proposed by Clark and Chalmers (1998).
} 
condition. $^{32}$ This is where my view can tip the scale: of the several candidates in our vicinity that are intrinsically eligible to be the referents of our 'I'-thoughts, we are the best satisfiers of these thoughts.

\subsection{Concerns about conventions}

The self-making view is a view not just about first-person language but also about first-person thought. One might nevertheless worry that it is not really a revisionary view about self-reference. Perhaps people are free to use the word ' $\mathrm{I}$ ' to refer to their limb-complements, but in that case they just use the word with a non-standard meaning, since the linguistic conventions rule against people being limb-complements. The objector could grant even that BIID patients can think of their limb-complements in some broadly first-personal way, while maintaining that they do not have true 'I'-thoughts about their limb-complements in the same sense most of us have true 'I'-thoughts about ourselves.

To address this objection, we should begin by asking what it would mean for BIID patients and the rest of us to mean different things by ' $\mathrm{I} .{ }^{33}$ It is customary in the literature on indexicals to distinguish between two kinds of meaning: if you say 'I am hungry' and I say 'I am hungry', there is intuitively a sense in which we say the same thing and a sense in which we say different things. Following Kaplan (1989a), I will refer to these as character and content, respectively, though there are many other ways to capture the distinction. ${ }^{34}$ Character is the kind of meaning that is constant across different uses of the same indexical, while content varies with the speaker. So when you and I use the word 'I' we use it with the same character but with different contents. This narrows down our question to whether BIID patients use the word 'I' with a different character than the rest of us. (That they use it with a different content is obvious and respected by the self-making view.)

\footnotetext{
${ }^{32}$ Note that certain popular restrictions, for example that persons like us are human animals, do not specify intrinsic conditions. Being a human animal is a maximal property, partly a matter of not being part of another human animal. However, the self-making view is still compatible with a close cousin of this view: human persons are intrinsically qualified to be human animals.

${ }^{33}$ I thank an anonymous referee for helping me sharpen my response here.

34 The distinction is not always captured in terms of different kinds of meaning. Perry $(1977,1979)$, for instance, argues that speakers uttering different tokens of the same 'I'-sentence express different propositions but are in the same type of belief state. Evans (1981) would say that the two speakers utter the sentence with the same (character-like) linguistic meaning but have different thoughts.
} 
On a standard view, the character of ' $\mathrm{I}$ ' is captured by the rule that every token of 'I' refers to the speaker who produces that token. The Problem of Overlappers forces us to realize that there is an obvious problem with this simple rule: there are many speakers for every token of ' $\mathrm{I}$ ', so there is no such thing as the speaker. We can at best say that every token of 'I' refers to $a$ speaker that produces it. The self-making view adds that for something to be a referent of ' $\mathrm{I}$ ', it is not enough that it is a speaker; it has to be the best candidate for making true the beliefs expressed by the speaker's 'I'-utterances. Does this imply that the character of 'I' varies across speakers depending on whether the speaker has BIID? I do not see why it would. Of course, most of us use 'I' to refer to a humanoid, while BIID patients use it to refer to a proper part of a humanoid. However, this does not mean that we use 'I' with different characters; indeed, it is implausible that 'I' has any built-in semantic restriction to humanoids. Recall the analogy with 'here' from \$2. The character of 'here' is usually specified by the rule that it picks out the speaker's location in every context, but as we know, there are many things that can count as the speaker's location. This does not imply that two speakers who choose to refer to differently sized regions with 'here' are using the word with different characters. Mutatis mutandis for the self-making view: just because I use the word 'I' for a humanoid and a BIID patient uses it for a proper part of a humanoid, it does not follow that we use the word with different characters.

\section{Conclusion}

In this paper I canvassed, admittedly in large brush strokes, the outlines of a promising alternative to standard versions of conventionalism: persons are, within certain constraints, self-made. There are reasons to find this view attractive, and while it has some surprising consequences, I do not find them repugnant. In fact, I find them liberating. I also considered several objections to the view, none of which seem compelling. There are many open issues for future investigation which I had no space to get into here but hope to discuss elsewhere. The most obvious one is the question of diachronic selfmaking: do people have a say in how long and under what conditions they persist? While the self-making view does not force on us an affirmative answer, it would be natural for its adherents to give one. In the present work I intentionally focused on the relation between 
persons and their parts at a time. The emerging picture offers novel and interesting ways of thinking about the metaphysics of persons and can be further developed in various directions. My present goal was just to put the self-making view on the table and argue that it deserves to be taken seriously. ${ }^{35}$

\section{References}

Almog, Joseph, John Perry and Howard Wettstein (eds) 1989: Themes from Kaplan. Oxford: Oxford University Press.

Árnadóttir, Steinvör Thöll 2010: 'Functionalism and Thinking Animals'. Philosophical Studies, 147, pp. 347-54.

Bach, Kent 1992: 'Intentions and Demonstrations'. Analysis, 52, pp. 140-6.

Baker, Lynne R. 2000: Persons and Bodies. Cambridge: Cambridge University Press.

Batthyany, Alexander and Avshalom Elitzur (eds) 2006: Mind and Its Place in the World: Non-Reductionist Approaches to the Ontology of Consciousness. Frankfurt: Ontos.

Bayne, Tim and Neil Levy 2005: 'Amputees by Choice: Body Integrity Identity Disorder and the Ethics of Amputation'. Journal of Applied Philosophy, 22, pp. 75-86.

Blatti, Stephen and Paul Snowdon (eds) forthcoming: Essays on Animalism. Oxford University Press.

Braddon-Mitchell, David and Kristie Miller 2004: 'How to be a Conventional Person'. Monist, 87, pp. 457-74.

Braddon-Mitchell, David and Caroline West 2001: 'Temporal Phase Pluralism'. Philosophy and Phenomenological Research, 62, pp. 59-83.

\footnotetext{
${ }^{35}$ For invaluable discussion and comments on several earlier versions of this paper, I am especially indebted to Matti Eklund and Ted Sider. For helpful comments and criticisms I am also grateful to Mohammad Azadpur, Gábor Bács, Karen Bennett, Oisín Deery, Björn Eriksson, Peter Fazekas, Alex Geddes, Philippe Lemoine, Peter Millican, Attila Mraz, Harold Noonan, Orsi Reich, Eric Rowe, Nico Silins, Rina Tzinman, Andrea Viggiano, the anonymous referees and editor of Mind, and audiences at the 2013 Meeting of the Pacific APA, the Central European University, Cornell University, Stockholm University, and the University of Oxford. Writing this paper felt almost like a family endeavour: my interest in the ethics of amputation was raised by my father Jozsef Kovacs, and the idea to connect it to puzzles in the metaphysics of persons was inspired by a conversation with my brother Adam Kovacs. Adam is a dental technician, and he frequently encounters people who want to get rid of some of their (?) parts.
} 
Burke, Michael B. 1994: 'Dion and Theon: An Essentialist Solution to an Ancient Puzzle'. Journal of Philosophy, 91, pp. 129-39.

2003: 'Is My Head a Person?'. In Petrus 2003, pp. 107-25.

Campbell, Keith, John Bacon and Lloyd Reinhardt (eds) 1993:

Ontology, Causality and Mind: Essays on the Philosophy of D.

M. Armstrong. Cambridge: Cambridge University Press.

Clark, Andy and David Chalmers 1998: 'The extended mind'. Analysis, 58, pp. 7-19.

Eklund, Matti 2004: 'Personal Identity, Concerns, and Indeterminacy'. Monist, 87, pp. 489-511.

Evans, Gareth 1981: 'Understanding Demonstratives'. In Parret and Bouveresse 1981, pp. 280-304.

Gill, Christopher (ed) 1990: The Person and the Human Mind. Oxford: Oxford University Press.

Guttenplan, Samuel (ed) 1994: A Companion to the Philosophy of Mind. Oxford: Blackwell.

Hale, Bob and Crispin Wright (eds) 1997: A Companion to Philosophy of Language. Oxford: Blackwell.

Hawley, Katherine 1998: 'Merricks on Whether Being Conscious is Intrinsic'. Mind, 107, pp. 841-3.

Hawthorne, John 2006: 'Epistemicism and Semantic Plasticity'. Oxford Studies in Metaphysics, 2, pp. 289-322.

Hershenov, David B. 2005: 'Persons as Proper Parts of Organisms'. Theoria, 71, pp. 29-37.

Hirsch, Eli 1982: The Concept of Identity. Oxford: Oxford University Press.

Hudson, Hud 2001: A Materialist Metaphysics of the Human Person. Ithaca: Cornell University Press.

- 2007: 'I Am Not an Animal!'. In van Inwagen and Zimmerman 2007, pp. 216-34.

Jackson, Frank 1998: 'Reference and Description Revisited'. Philosophical Perspectives, 12, pp. 201-18.

Johnston, Mark 1989: 'Relativism and the Self'. In Krausz 1989, pp. 441-72.

2007: "Human Beings" Revisited: My Body is Not an Animal'. Oxford Studies in Metaphysics, 3, pp. 35-74.

Kaplan, David 1989a: 'Demonstratives'. In Almog, Perry, and Wettstein 1989. pp. 481-563.

1989b: 'Afterthoughts'. Almog, Perry, and Wettstein 1989, pp. 565-614. 
Kovacs, David Mark 2010: 'Is There a Conservative Solution to the Many Thinkers Problem?'. Ratio, 23, pp. 275-90.

Kovacs, Jozsef 2009: 'Whose Identity is It Anyway?'. American Journal of Bioethics, 9, pp. 44-5.

Krausz, Michael (ed) 1989: Relativism: Interpretation and Confrontation. Notre Dame, IN: University of Notre Dame Press. Levy, Neil 2009: 'Autonomy is (Largely) Irrelevant'. American Journal of Bioethics, 9, pp. 50-1.

Lewis, David 1974: 'Radical Interpretation'. Synthese, 23, pp. 331-44.

- 1976: 'Survival and Identity'. In Rorty 1976, pp. 17-40.

1979: 'Attitudes De Dicto and De Se'. Philosophical Review, 88, pp. $513-43$.

1983: 'New work for a theory of universals'. Australasian Journal of Philosophy, 61, pp. 343-77.

1993: 'Many, but almost One'. In Campbell, Bacon and Reinhardt 1993, pp. 23-38.

- 1994: 'Reduction of Mind'. In Guttenplan 1994, pp. 412-31.

Madden, Rory 2011a: 'Intention and the Self'. Proceedings of the Aristotelian Society, 111, pp. 325-51.

2011b: 'Externalism and Brain Transplants'. Oxford Studies in Metaphysics, 6, pp. 287-316.

_forthcoming: 'Thinking Parts'. In Blatti and Snowdon forthcoming.

McMahan, Jeff 2002: The Ethics of Killing: Problems at the Margins of Life. Oxford: Oxford University Press.

Merricks, Trenton 1998: 'Against the Doctrine of Microphysical Supervenience'. Mind, 107, pp. 59-71.

2001: 'Realism about Personal Identity over Time'. Philosophical Perspectives, 15, pp. 173-86.

Miller, Kristie 2013: “Personal Identity" minus the persons'. Philosophical Studies, 166, pp. S91-S109.

Morgan, Daniel 2009: 'Can you think my 'I'-thoughts?'. Philosophical Quarterly, 59, pp. 68-85.

Müller, Sabine 2009: 'Body Integrity Identity Disorder (BIID)-Is the Amputation of Healthy Limbs Ethically Justified?'. American Journal of Bioethics, 9, pp. 36-43.

Noonan, Harold W. 1998: 'Animalism Versus Lockeanism: A Current Controversy'. Philosophical Quarterly, 48, pp. 302-18.

2001: 'The Epistemological Problem of Relativism - Reply to Olson'. Philosophical Studies, 104, pp. 323-36. 
2010: 'The thinking animal problem and personal pronoun revisionism'. Analysis, 70, pp. 93-8.

Nozick, Robert 1981: Philosophical Explanations. Cambridge, MA: Harvard University Press.

Olson, Eric 1995: 'Why I Have No Hands'. Theoria, 61, pp. 182-97. 1997a: The Human Animal. New York: Oxford University Press. 1997b: 'Relativism and Persistence'. Philosophical Studies, 88, pp. 141-62.

2002: 'Thinking Animals and the Reference of "I"'. Philosophical Topics, 30, pp. 189-207.

2007: What Are We?. New York: Oxford University Press. Parfit, Derek 1984: Reasons and Persons. Oxford: Clarendon Press. 2012: 'We Are Not Human Beings'. Philosophy, 87, pp. 5-28.

Parret, Herman and Jacques Bouveresse 1981 (eds): Meaning and Understanding. New York: de Gruyter.

Perry, John 1977: 'Frege on Demonstratives'. Philosophical Review, 86, pp. 474-97.

1979: 'The Problem of the Essential Indexical'. Nồs, 13, pp. 321.

— 1997: 'Indexicals and Demonstratives'. In Hale and Wright 1997, pp. 586-612.

Petrus, Klaus (ed) 2003: On Human Persons. Frankfurt: Ontos.

Recanati, François 2001: 'Are "here" and "now" indexicals?'. Texte, $127 / 8$, pp. $115-27$.

Reimer, Marga 1991: 'Demonstratives, Demonstrations, and Demonstrata'. Philosophical Studies, 63, pp. 187-202.

Robinson, Howard 2006: 'Personal Identity, the Self and Time'. In Batthyany and Elitzur, pp. 245-67.

Rorty, Amelie O. (ed) 1976: The Identities of Persons. Berkeley and LA: University of California Press.

Rovane, Carol 1998: The Bounds of Agency. Princeton, NJ: Princeton University Press.

Schwarz, Wolfgang 2014: 'Against Magnetism'. Australasian Journal of Philosophy, 92, pp. 17-36.

Shoemaker, Sydney 1999: 'Self, body, and coincidence'. Proceedings of the Aristotelian Society, supp. vol. 73, pp. 287-306.

Sidelle, Alan 1999: 'On the Prospects for a Theory of Personal Identity'. Philosophical Topics, 26, pp. 351-72.

Sider, Theodore 2001a: 'Criteria of Personal Identity and the Limits of Conceptual Analysis'. Philosophical Perspectives, 15, pp. 189-209. 
2001b: 'Maximality and Intrinsic Properties'. Philosophy and Phenomenological Research, 63, pp. 357-64.

2003: 'Maximality and Microphysical Supervenience'. Philosophy and Phenomenological Research, 66, pp. 139-49.

2011: Writing the Book of the World. Oxford: Clarendon Press.

Snowdon, Paul F. 1990: 'Persons, Animals, and Ourselves'. In Gill 1990, pp. 83-107.

Sutton, Catherine S. 2014: 'The Supervenience Solution to the TooMany-Thinkers Problem'. Philosophical Quarterly, 64, pp. 619-39. Unger, Peter 1980: 'The Problem of the Many'. Midwest Studies in Philosophy, 5, pp. 411-67.

1990: Identity, Consciousness, and Value. Oxford: Oxford University Press.

van Inwagen, Peter 1981: 'The Doctrine of Arbitrary Undetached Parts'. Pacific Philosophical Quarterly, 62, pp. 123-37.

— 1990: Material Beings. Ithaca: Cornell University Press.

van Inwagen, Peter and Dean W. Zimmerman (eds) 2007: Persons: Human and Divine. Oxford: Oxford University Press.

Weatherson, Brian 2013: 'The Role of Naturalness in Lewis's Theory of Meaning'. Journal for the History of Analytical Philosophy 1 (10).

Williams, J.R.G. 2013: 'Part-Intrinsicality'. Noûs, 47, pp. 431-52.

Zimmerman, Dean W. 2003a: 'Material People'. In Zimmerman 2003b, pp. 491-526.

Zimmerman, Dean W. (ed) 2003b: The Oxford Handbook of Metaphysics. Oxford: Oxford University Press. 
